\title{
THE SMALL PULMONARY BLOOD VESSELS IN ATRIAL SEPTAL DEFECT
}

\author{
BY \\ DONALD HEATH AND WILLIAM WHITAKER
}

From the Regional Cardiovascular Centre, City General Hospital, and the University Department of Medicine, Sheffield

Received October 24, 1956

The development of direct methods of recording pulmonary artery pressure by cardiac catheterization or bronchoscopically and the advance of cardiac surgery have stimulated an interest in pulmonary hypertension and have made it possible to study the relation of morbid anatomical and dynamic changes in the pulmonary circulation. In recent years there have been many reports of abnormal pulmonary vessels in patients with pulmonary hypertension and these suggest that there is a histological pattern characteristic of this disorder. Although pulmonary artery blood pressures may range from normal to levels of the order of the systemic blood pressure in patients with atrial septal defects there have been but few descriptions of lesions in the small pulmonary blood vessels in this anomaly (Welch and Kinney, 1948; and Evans, 1951) and an examination of the pulmonary vascular histology in a group of such cases seemed likely to provide further evidence of anatomical changes occurring with pulmonary hypertension.

In the present investigation the pulmonary blood vessels from a small group of patients with atrial septal defects, where the pulmonary artery blood pressures were known to range from normal to severe pulmonary hypertension, were examined histologically. The anatomical changes were related to the pulmonary artery blood pressures and there appeared to be well defined histological pictures characteristic of normal and of severely raised pulmonary arterial pressure.

Method. Specimens of lung were obtained at autopsy from five patients with atrial defect whose pulmonary artery pressures had been previously recorded by cardiac catheterization. Four died following attempts to close the septal defects while the other (Case 3) died from a paroxysm of tachycardia. Sections of lung from all cases were stained to show elastic by the Lawson modification of the Weigert-Sheridan method and counterstained with van Gieson's stain. Serial sections were examined from a block of lung in Case 3.

\section{RESULTS}

The histological findings in the pulmonary blood vessels of the patients in this series are shown in Table I together with the pulmonary arterial pressures. In the patients with normal pressures (Cases 1 and 2) the media of the muscular pulmonary arteries (100 to $1000 \mu$ in diameter) was thin and consisted of smooth muscle, usually not exceeding 5 per cent of the external diameter of the vessel. It was bounded by thin, unsplit elastic membranes, and the adventitia was thin. The arterioles (less than $100 \mu$ in external diameter) had no media and usually there was only a single elastic lamina between a thin adventitia and the intima. The venules were identical in structure with the arterioles. There was no thrombosis and the degree of intimal sclerosis was less than would be expected as a normal age change (Heath and Whitaker, 1955b).

In the patients with severe pulmonary arterial hypertension the elastic pulmonary arteries were atheromatous. The muscular pulmonary arteries and pulmonary arterioles were grossly abnormal 
TABLE I

The Pulmonary Arterial Pressures and Histological Features of the Muscular Pulmonary Arteries and Arterioles in Atrial Septal Defect

\begin{tabular}{|c|c|c|c|c|c|c|c|c|}
\hline \multirow[b]{2}{*}{ Case } & \multirow[b]{2}{*}{ Sex } & \multirow[b]{2}{*}{ Age } & \multirow[b]{2}{*}{$\begin{array}{c}\text { Pulmonary } \\
\text { artery } \\
\text { mean } \\
\text { pressure } \\
\text { (mm. Hg) }\end{array}$} & \multicolumn{2}{|c|}{$\begin{array}{l}\text { Vessels below } 100 \mu \\
\text { in external diameter }\end{array}$} & \multicolumn{3}{|c|}{ Muscular pulmonary arteries } \\
\hline & & & & $\begin{array}{c}\text { Distinct } \\
\text { muscular } \\
\text { media } \\
\text { with two } \\
\text { laminæ }\end{array}$ & $\begin{array}{c}\text { Severe } \\
\text { intimal } \\
\text { proliferation } \\
\text { of fibrous } \\
\text { tissue } \\
\text { exceeding } \\
\text { normal age } \\
\text { change }\end{array}$ & $\begin{array}{c}\text { Medial } \\
\text { hypertrophy } \\
\text { (media } \\
\text { exceeding } \\
15 \% \text { of } \\
\text { external } \\
\text { diameter } \\
\text { of vessel) }\end{array}$ & $\begin{array}{c}\text { Severe } \\
\text { intimal } \\
\text { proliferation } \\
\text { of fibrous } \\
\text { tissue } \\
\text { exceeding } \\
\text { normal age } \\
\text { change }\end{array}$ & $\begin{array}{l}\text { Thick } \\
\text { adventitia }\end{array}$ \\
\hline $\begin{array}{l}1 \\
2 \\
3 \\
4 \\
5\end{array}$ & $\begin{array}{l}F \\
F \\
F \\
F \\
F\end{array}$ & $\begin{array}{l}34 \\
53 \\
29 \\
39 \\
25\end{array}$ & $\begin{array}{r}16 \\
20 \\
58 \\
70 \\
108\end{array}$ & $\begin{array}{l}- \\
- \\
+ \\
+ \\
+\end{array}$ & $\begin{array}{l}- \\
- \\
+ \\
+ \\
+\end{array}$ & $\begin{array}{l}- \\
\overline{+} \\
+ \\
+\end{array}$ & $\begin{array}{l}- \\
\overline{+} \\
+ \\
+\end{array}$ & $\begin{array}{l}- \\
\overline{+} \\
+ \\
+\end{array}$ \\
\hline
\end{tabular}

(Fig. 1 and 2). The media of the small muscular pulmonary arteries was hypertrophied to a thickness exceeding 15 per cent of the external diameter of the vessel (Fig. 1C and D). The elastic membranes were thick. The adventitia was thick and fibrous and in some there was intimal proliferation of fibroelastic tissue leading to partial occlusion of the vessel (Fig. 1C). The pulmonary arterioles (less than $100 \mu$ in diameter) (Fig. 1A and B) had a distinct muscular media lined by thickened internal and external elastic membranes. There was intimal proliferation of fibroelastic tissue (Fig. 1A and B). The adventitia was thick and fibrous. In some the proliferated intimal fibrous tissue had completely disorganized the structure of the vessel. There was intimal fibrosis in the pulmonary veins.

In Cases 3 and 4 many of the small muscular pulmonary arteries and the hypertensive arterioles terminated by sudden dilatation to form thin-walled vessels which were lined by a single elastic lamina and filled by what appeared to be organizing blood clot which had undergone multiple recanalization by thin-walled capillaries. Fig. 2A shows a hypertensive pulmonary arteriole of external diameter $100 \mu$ which has expanded to form a dilated thin-walled vessel, $195 \mu$ in diameter. The expanded termination of the hypertensive arterioles narrowed abruptly to form capillaries which had patent lumina about $10 \mu$ in diameter (Fig. 2A and B). Some of the arterioles ended normally in patent capillaries without first undergoing dilatation.

\section{DisCUSSION}

It would appear from this study that there are characteristic histological appearances in the pulmonary vasculature in atrial septal defect with normal pulmonary artery blood pressure and severe pulmonary arterial hypertension. Heath and Whitaker (1955a) reported identical findings in patients with patent ductus arteriosus and it seems, as might be expected, that these appearances are unrelated to the underlying cardiac anomaly associated with the pulmonary hypertension.

In Cases 1 and 2 of the present series of patients with atrial septal defect and in eight patients with patent ductus arteriosus reported by Heath and Whitaker (1955a) the pulmonary blood vessels were normal when there was a high pulmonary blood flow and a normal pulmonary artery blood pressure, which suggests that anatomical changes in the blood vessels of the lung do not follow directly from an increased pulmonary blood flow. Similarly Welch and Kinney (1948) studied 25 cases of atrial septal defect and found that in the 13 uncomplicated by an additional cardiac anomaly the pulmonary vascular lesions were not greater than those in a control group of comparable ages. Only one of these cases had been subjected to cardiac catheterization and the pulmonary artery pressure was found to be $35 / 10 \mathrm{~mm}$. $\mathrm{Hg}$ with a pulmonary blood flow of 14 litres 

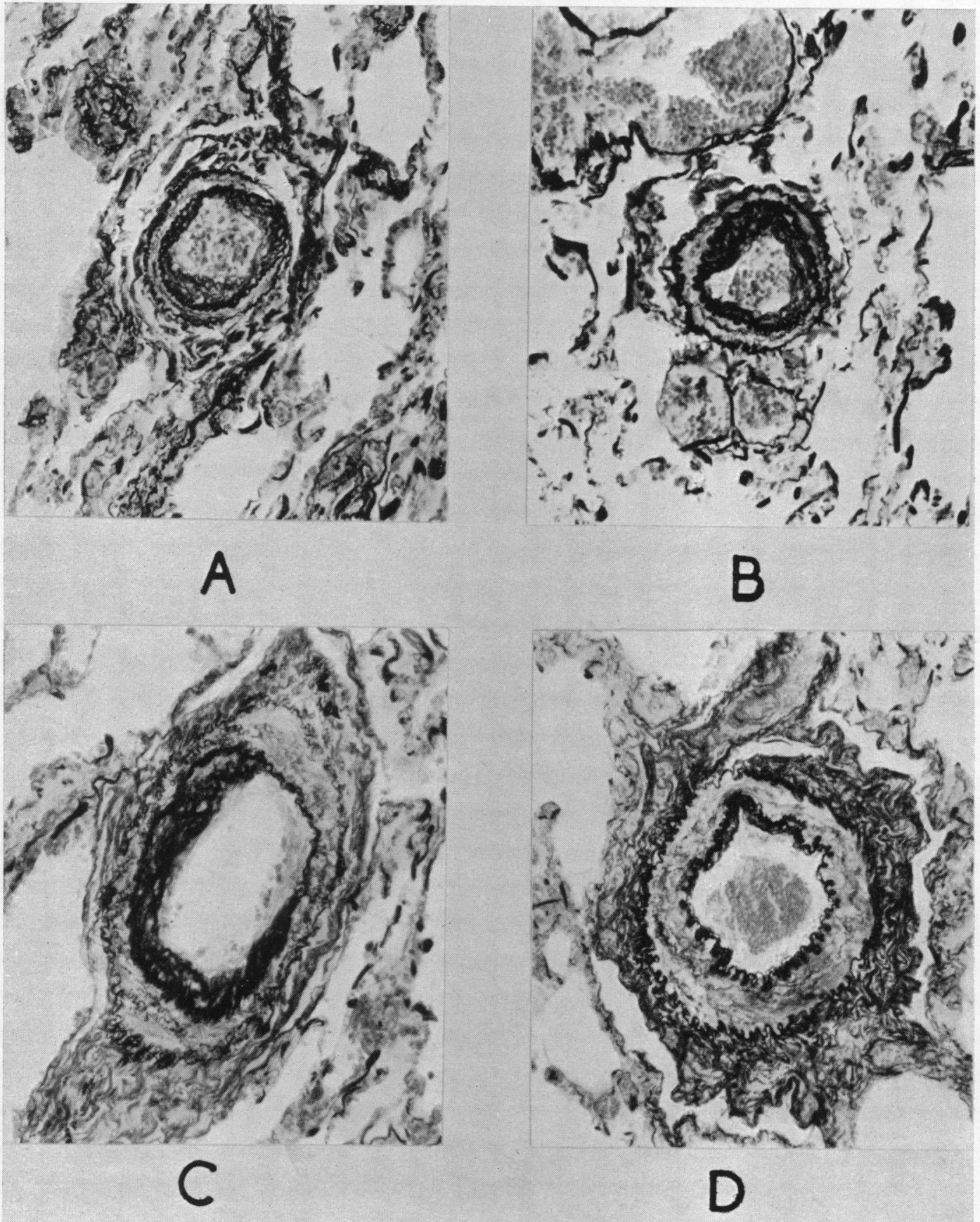

Fig. 1.-All sections from Case 4 whose pulmonary arterial mean pressure was $70 \mathrm{~mm}$. $\mathrm{Hg}$. All stained to show elastic by the Lawson modification of the Weigert-Sheridan method, and counterstained with van Gieson to demonstrate muscle and collagen. Magnification $\times 150$ except in (A) where it is $\times 140$. (A) and (B) Transverse sections of pulmonary arterioles. A distinct media is present between internal and external elastic laminx. There is intimal proliferation of fibroelastic tissue (elastosis). (C) and (D) Transverse sections of muscular pulmonary arteries. There is adventitial fibrosis, a hypertrophied media, and prominent internal elastic membranes. In (C) there is intimal proliferation of fibroelastic tissue. 

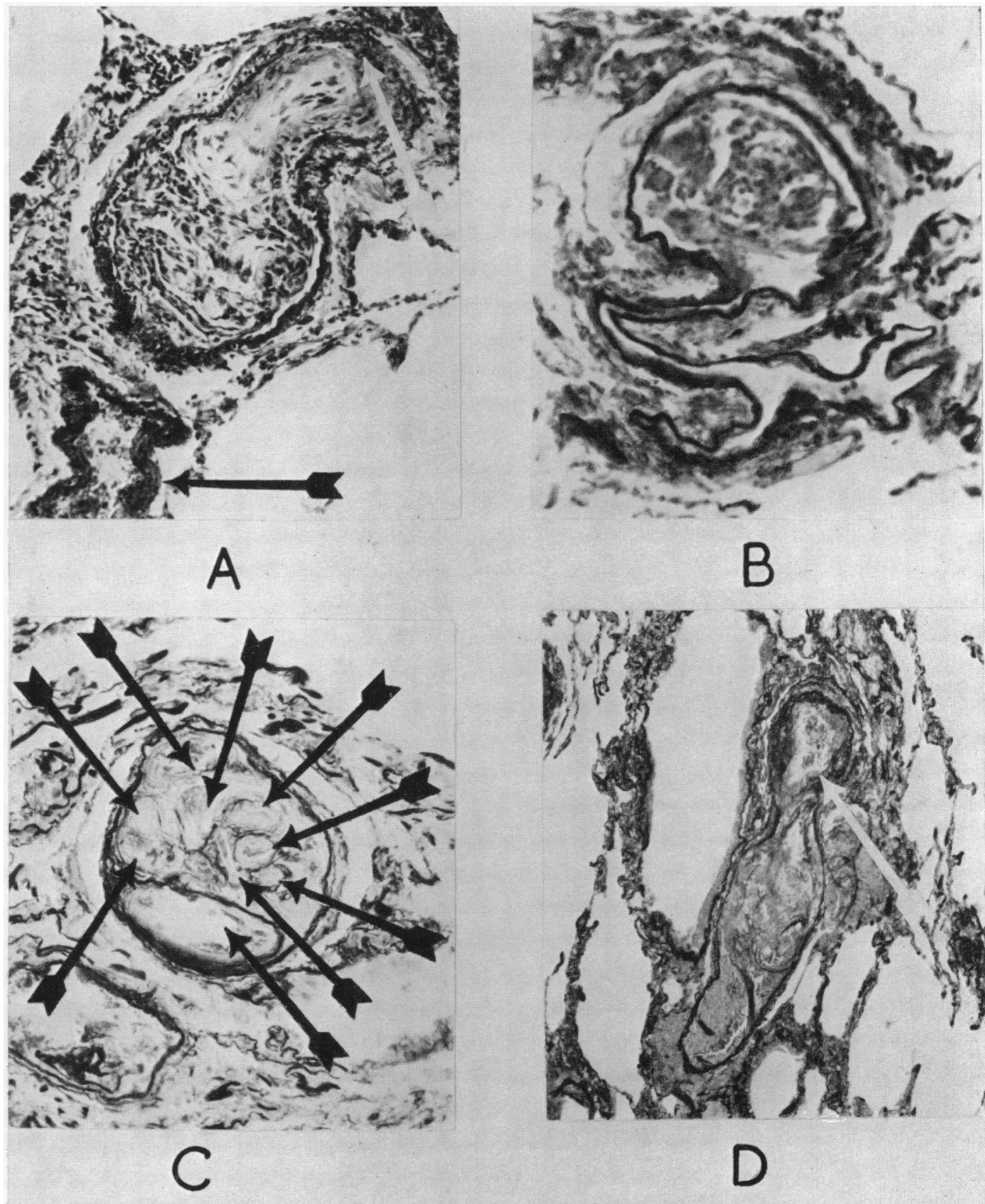

FIG. 2.-All sections stained to show elastic by the Lawson modification of the Weigert-Sheridan method, and counter-stained with van Gieson to demonstrate muscle and collagen. (A) Longitudinal section of the termination of a hypertensive pulmonary arteriole, $100 \mu$ in diameter, with distinct media between internal and external elastic laminæ, and intimal fibrosis. This vessel, indicated by a white arrow, expands abruptly to form a dilated vessel, $195 \mu$ in diameter lined by a single elastic lamina, which contains organizing blood clot. The dilated vessel narrows to give rise to a capillary indicated by a black arrow (X 150, Case 3). (B) Section through a dilated vessel similar to that described in (A). This is lined by a single elastic lamina and contains organizing blood clot. The sudden narrowing of this vessel to 
a minute but there was no evidence that any of the 13 had pulmonary hypertension. Nine additional cases of atrial septal defect were thought to have had rheumatic involvement of the mitral valve also and, of these, eight had right ventricular hypertrophy and pulmonary vascular lesions. This led Welch and Kinney to conclude that cases with co-existing atrial septal defect and mitral stenosis had constant atherosclerotic changes in the pulmonary vessels. Although the authors thought that these changes were due to an increased flow of blood from the left atrium to the lungs via the right chambers of the heart following the obstruction at the mitral valve, it seems more likely that pulmonary arterial hypertension, which is known to be frequently associated with mitral stenosis was the ætiological factor.

The three patients in the present series in whom cardiac catheterization had demonstrated severe pulmonary arterial hypertension (Cases 3, 4, and 5) showed medial hypertrophy and severe intimal fibrosis in the muscular pulmonary arteries, and a distinct muscular media with two elastic laminæ and severe intimal fibrosis in the pulmonary arterioles. Evans (1951) has described similar changes in another case of atrial septal defect complicated by severe pulmonary arterial hypertension. They have been described commonly in patients in whom severely raised pulmonary artery blood pressure has been associated with Eisenmenger's complex (Stewart and Crawford, 1933; Old and Russell, 1950; Brown et al., 1955), ventricular septal defect (Heath et al., 1956), patent ductus arteriosus (Johnson et al., 1950; Cosh, 1953; Dammann et al., 1953; Hultgren et al., 1953; and Whitaker et al., 1955), idiopathic pulmonary hypertension (Gilmour and Evans, 1946; Branwood, 1954; Aitchison and Richmond, 1955; and Heath et al., 1957), and mitral stenosis (Larrabee et al., 1949; Henry, 1952; Hicks, 1953; Denst et al., 1954; and Heath and Whitaker, 1955b). Furthermore, these vascular changes, which may be associated with pulmonary atheroma, medial necrosis confined to the blood vessels of the lung, dilatation of the branches of the muscular pulmonary arteries, and the development of bronchopulmonary anastomoses (Heath and Whitaker, 1956) appear to be associated with a clinical picture that is dominated by the clinical signs and symptoms of pulmonary arterial hypertension. The combination of these specific anatomical changes and this characteristic group of clinical symptoms and signs constitutes a distinct clinicopathological syndrome termed the pulmonary vascular obstruction syndrome by Cutler et al. (1954) and hypertensive pulmonary vascular disease by Heath and Whitaker (1956).

The additional histological appearances noted in Cases 3 and 4 are probably significant, for when fluid passes through a narrow channel into a dilated vessel or a large number of channels of similar diameter under a head of pressure, the flow is immediately slowed and the pressure diminished. Thus in the present case, blood at the severely raised pulmonary artery blood pressure in the muscular pulmonary arteries and pulmonary arterioles narrowed by intimal fibrosis entered dilated terminations containing numerous channels and this probably resulted in lowering of the pressure and slowing of the pulmonary blood flow at these points.

Vessels below $100 \mu$ in diameter with a distinct muscular media, such as have been described as characteristic of pulmonary arterial hypertension in a preceding paragraph, do not have the same significance when seen in the neonatal period. Civin and Edwards (1951) have pointed out that such vessels occur normally in the fœtal and neonatal period as the intralobular arteries, which are the developing muscular pulmonary arteries, and this has been confirmed by one of us (D. H.) in the examination of lungs from control infant cases (Heath, 1956). It needs to be stressed, however, that severe intimal fibrosis never occurs normally in the lung in the neonatal period and is indicative of pulmonary arterial hypertension.

Legend to Fig. 2 (continued from p. 330).

produce pulmonary capillaries is illustrated $(\times 250$, Case 3$)$. (C) Transverse sections through another of these dilated, thin-walled terminations of hypertensive pulmonary arterioles, showing the numerous channels, indicated by arrows, in the recanalized thrombus $(\times 140$, Case 4$)$. (D) Longitudinal section of the termination of a hypertensive pulmonary arteriole with distinct media between internal and external elastic laminæ, and intimal fibrosis. This vessel, indicated by a white arrow, expands abruptly to form a dilated vessel lined by a single elastic lamina and containing organized, recanalized thrombus ( $\times 85$, Case 4$)$. 
Specimens of lung were obtained at autopsy from five patients with atrial septal defect whose pulmonary artery blood pressures had been previously recorded by cardiac catheterization. A close relationship was found between these pressures and the histological appearance of the small pulmonary blood vessels.

The pulmonary blood vessels were normal in two patients with normal pulmonary arterial pressure but increased pulmonary blood flow. In three patients with pulmonary hypertension there was medial hypertrophy and severe intimal fibrosis in the muscular pulmonary arteries $(100$ to $1000 \mu)$, and a distinct muscular media with two elastic laminæ in the pulmonary arterioles $(<100 \mu)$.

In two patients the hypertensive arterioles terminated by sudden dilatation to form thin-walled vessels that were lined by a single elastic lamina and filled by what appeared to be organizing blood clot which had undergone multiple recanalization. It is considered that such an anatomical structure is of significance in producing a local lowering of pulmonary artery blood pressure.

We are most grateful to Professor P. R. Allison, Dr. O. Brenner, and Dr. J. W. Brown for allowing us to study the autopsy material from patients who had been under their care and for allowing us access to the relevant cardiac catheterization data.

\section{REFERENCES}

Aitchison, J. D., and Richmond, H. G. (1954), Brit. Heart J., 17, 312.

Branwood, A. W. (1954). Edin. med. J., 61, 332.

Brown, J. W., Heath, D., and Whitaker, W. (1955). Brit. Heart J., 17, 273.

Civin, W. H., and Edwards, J. E. (1951). Arch. Path., 51, 192.

Cosh, J. (1953). Brit. Heart J., 15, 423.

Cutler, J. G., Nadas, A. S., Goodale, W. T., Hickler, R. B., and Rudolph, A. M. (1954). Amer. J. Med., $17,485$.

Dammann, J. F., Jnr., Berthrong, M., and Bing, R. J. (1953). Bull. Johns Hopk. Hosp., $92,128$.

Denst, J., Edwards, A., Neuberger, K. T., and Blount, S. G. (1954). Amer. Heart J., 48, 506.

Evans, W. (1951). Proc. roy. Soc. Med., 44, 600.

Gilmour, J. R., and Evans, W. (1946). J. Path. Bact., 58, 687.

Heath, D. (1956). M.D. Thesis University of Sheffield.

- and Whitaker, W. (1955a). J. Path. Bact., 70, 285.

(1955b). J. Path. Bact., 70, 291.

- - (1956). Circulation, 14, 323.

-, Whitaker, W., and Brown, J. W. (1957). Brit. Heart J., 19, 83.

Henry, E. W. (1952). Brit. Heart J., 14, 406.

Hicks, J. D. (1953). J. Path. Bact., 65, 333.

Hultgren, H., Selzer, A., Purdy, A., Holman, E., and Gerbode, F. (1953). Circulation, $8,15$.

Johnson, R. E., Wermer, P., Kuschner, M., and Cournand, A. (1950). Circulation, 1, 1293.

Larrabee, W. F., Parker, R. L., and Edwards, J. E. (1949). Proc. Staff Meet., Mayo Clin., $24,316$.

Old, J. W., and Russell, W. O. (1950). Amer. J. Path., 26, 789.

Stewart, H. L., and Crawford, B. L. (1933). Amer. J. Path., 9, 637.

Welch, K. J., and Kinney, T. D. (1948). Amer. J. Path., 24, 729.

Whitaker, W., Heath, D., and Brown, J. W. (1955). Brit. Heart J., 17, 121. 